\title{
Inhibitory effect of zirconium oxide nanoparticles on Candida albicans adhesion to repaired polymethyl methacrylate denture bases and interim removable prostheses: a new approach for denture stomatitis prevention
}

This article was published in the following Dove Press journal:

International Journal of Nanomedicine

28 July 2017

Number of times this article has been viewed

\author{
Mohammed M Gad' \\ Ahmad M Al-Thobity' \\ Suliman Y Shahin ${ }^{2}$ \\ Badar T Alsaqer ${ }^{3}$ \\ Aiman A Ali 4,5 \\ 'Department of Substitutive Dental \\ Sciences, ${ }^{2}$ Department of Preventive \\ Dental Sciences, College of Dentistry, \\ ${ }^{3}$ Department of Microbiology, \\ College of Medicine, ${ }^{4}$ Department \\ of Biomedical Dental Sciences, \\ College of Dentistry, University of \\ Dammam, Dammam, Saudi Arabia; \\ ${ }^{5}$ Oral Pathology and Medicine, College \\ of Dentistry, University of Toronto, \\ Toronto, ON, Canada
}

Background: Despite drawbacks, cold-cured acrylic resin is still the most common material used in denture repair. Zirconia nanoparticles were among the reinforcements added to increase the strength of the resin. The effect on Candida due to the addition of zirconia nanoparticles to the resin has not been investigated.

Purpose: The aim of this study was to evaluate the effect of zirconia nanoparticles added to cold-cured acrylic resin on Candida albicans adhesion.

Materials and methods: A total of 120 acrylic resin specimens with dimensions measuring $22 \times 10 \times 2.5 \mathrm{~mm}^{3}$ were prepared and divided into two equal groups. One group (repair) comprised heat-polymerized specimens that were sectioned at the center and prepared to create a $2 \mathrm{~mm}$ repair area that was repaired with cold-cured resin reinforced with $0 \% \mathrm{wt}, 2.5 \% \mathrm{wt}, 5 \% \mathrm{wt}$, and $7.5 \%$ wt zirconia nanoparticles. The second group contained intact cold-cured acrylic resin specimens reinforced with $0 \% \mathrm{wt}, 2.5 \% \mathrm{wt}, 5 \% \mathrm{wt}$, and $7.5 \% \mathrm{wt}$ zirconia nanoparticles. Specimens were incubated at $37^{\circ} \mathrm{C}$ in artificial saliva containing C. albicans, and the effect of zirconia nanoparticles on C. albicans was assessed using two methods: 1) a slide count method and 2) a direct culture test. Variations in the number of living Candida were observed in relation to the different concentrations of zirconia nanoparticles. Analysis of variance (ANOVA) and post hoc Tukey's tests were performed for data analysis. If the $P$-value was $\leq 0.05$, then the difference was considered as statistically significant.

Results: It was found that $C$. albicans adhesion to repaired specimens was significantly decreased by the addition of zirconia nanoparticles $(P<0.00001)$ in comparison with the control group. Intact cold-cured groups and groups repaired with cold-cured resin reinforced with $7.5 \% \mathrm{wt}$ zirconia nanoparticles showed the lowest Candida count. Tukey's test showed a significant difference between the repaired group and the intact cold-cured group, while the later demonstrated a lower Candida count.

Conclusion: The addition of zirconia nanoparticles to cold-cured acrylic resin is an effective method for reducing Candida adhesion to repaired polymethyl methacrylate (PMMA) denture bases and cold-cured removable prosthesis.

Clinical significance: Based on the results of the current study, zirconia nanoparticles have an antifungal effect, which could be incorporated in the repair material for repairing denture bases and in PMMA removable prostheses as a possible approach for denture stomatitis prevention. Keywords: Candida albicans, denture base repair, PMMA, interim prosthesis, reinforcement, zirconium oxide nanoparticles
Correspondence: Mohammed M Gad Sciences, College of Dentistry, University of Dammam, PO Box 1982 Dammam 3|44I, Saudi Arabia

Tel +966592502080

Fax +966 I3 8572624

Email dr.gad@hotmail.com 


\section{Introduction}

Polymethyl methacrylate (PMMA) is a material used for the fabrication of complete and partial removable dentures. However, this material has some drawbacks, which still prove problematic in some clinical and prosthodontic practices, with regard to the surface properties, such as surface roughness, apparent porosity, and so on, that can act as a reservoir for microorganisms. ${ }^{1,2}$ Moreover, improper denture hygiene results in surface scratches, debris accumulation, and biofilm formation, which contributes to inflammatory changes in the neighboring mucosa and causes denture stomatitis (DS). ${ }^{1-3}$

DS is a disease associated with Candida albicans, and it is a common repetitive problem for complete-denture wearers. ${ }^{1}$ The initial attachment and adhesion of $C$. albicans to the intaglio surface of a denture base is an essential step in the colonization and pathogenesis that causes DS. ${ }^{1-4}$ Barbeau et al ${ }^{5}$ mentioned that the prevention of DS starts with essential plaque control through patient education on thorough daily denture cleaning. It was stated that mechanical cleaning methods are inadequate to entirely reduce microorganisms on denture surfaces. ${ }^{5,6}$ Therefore, many attempts have been made to reduce C. albicans adhesion and subsequent colonization on the denture base through the use of a variety of antifungal agents, but this treatment method has proven to be a short-term therapy and not always effective. ${ }^{2,7}$ Moreover, many approaches to overcoming fungal adhesion to a denture base have been taken, such as surface modification by using different coatings $\mathrm{s}^{8-11}$ or incorporating an antifungal additive into a PMMA denture base. ${ }^{11}$

Denture base fracture while in use is the most frequent problem, and it requires denture replacement or repair. ${ }^{12}$ A new denture fabrication is costly and time consuming, so denture repair is usually the preferred option. To restore the original shape and strength, there are several repair resins available with enhanced laboratory and clinical properties. Heat-polymerized acrylic resin materials have higher mechanical properties compared with light and cold-cured acrylic resins. ${ }^{13,14}$ However, they need laboratory packing and flasking procedures, which are not only time consuming but also associated with the risk of denture distortion by heat. ${ }^{15,16}$

The most popular denture repair material is cold-cured acrylic resin, first because of its easy handling, which saves chairside time, and second, because it does not require laboratory processing. Moreover, the patient spends less time without a denture during the repair process. ${ }^{17}$ Unfortunately, the low surface properties and porosity of cold-cured repair resin increase the susceptibility to Candida adhesion. ${ }^{18}$ Şahin et al tested the effect of heat-polymerized, cold-cured, microwave-cured, and light-cured repair materials for flexural strength and Candida adhesion, and they found that the repair materials were highly susceptible to C. albicans adhesion. The flexural strengths of these materials were not satisfactory for prosthodontic practice. ${ }^{20}$ Moreover, repaired dentures, which are made of two different resins, that is, the heat-polymerized old denture base and the cold-cured repair resin, in addition to the junction between both resins, increase the susceptibility to Candida adhesion. Therefore, various studies have investigated the effect of reinforcement materials and surface treatment on the physical properties of repaired dentures..$^{17,21}$

Some applications of cold-cured acrylic resin include interim removable prostheses, maxillofacial prostheses, orthodontic removable appliances, and implant-supported fixed interim prostheses. ${ }^{16,17,21,24}$ All prosthetic replacements must be carefully designed, properly executed, meticulously cleaned, and preserved during the intended service time of the temporary restoration. ${ }^{25}$ The interim removable prosthesis is a prosthesis designed to enhance esthetics, stabilization, and/or function for a limited period of time, which can be replaced later by a definite prosthesis. ${ }^{22}$ Interim prostheses provide an immediate esthetic solution until healing of the periodontium at the extraction site is completed. ${ }^{23}$ Despite the wide range of cold-cured acrylic resin applications as interim prostheses, it has physical and mechanical drawbacks that can be improved by the addition of nanoparticles. The versatility of clinical applications that requires the use of cold-cured acrylic resin material in dental practice supports the importance of studying the antifungal effects of zirconia nanoparticles in the resins.

Nano-sized materials have contributed to advanced applications in the field of nanomedicine and biomedical sciences due to their brilliant physical and chemical properties. Among nanoparticles are metal oxides that are valuable not only due to their wide variety of physical and chemical properties but also due to their antibacterial effect. ${ }^{26}$ The chemical reactivity and surface energy of nanoparticles play a central role in defining the antibacterial and antifungal properties. ${ }^{27}$ Zirconium oxide nanoparticles (nano- $\mathrm{ZrO}_{2}$ ) have received a special attention for their attractive scientific and technological aspects. ${ }^{28} \mathrm{Nano}-\mathrm{ZrO}_{2}$ particles are also able to possess remarkable antimicrobial properties. Several studies on nano- $\mathrm{ZrO}_{2}$ have demonstrated the antibacterial and antifungal effects on C. albicans and Aspergillus niger. ${ }^{28}$ Jangra et $\mathrm{a}^{29}$ found that nano- $\mathrm{ZrO}_{2}$ worked preliminarily on bacterial strains of Escherichia coli and Staphylococcus aureus and on the fungal strain of $A$. niger and mainly showed activity against $E$. coli. Gowri et al explained that the improved 
antibacterial activity of nano- $\mathrm{ZrO}_{2}$ might be attributed to active oxygen species produced from the nano- $\mathrm{ZrO}$, which in turn causes a disruption of the cell membrane of microorganisms. This disruption increases the permeability of the cell membrane, leading to nano- $\mathrm{ZrO}_{2}$ accumulation in the membrane and cytoplasmic regions of the cells. ${ }^{28}$ Owing to its high surface area, nano- $\mathrm{ZrO}_{2}$ particles show a significant inhibition effect against fungal strains. Nano- $\mathrm{ZrO}_{2}$ can actively inhibit the growth of fungal strains by interfering with cell function and causing deformation in fungal hyphae. ${ }^{29,30}$

Recently, much attention has been directed toward the incorporation of nanoparticles into PMMA to improve its properties. Nano- $\mathrm{ZrO}_{2}$ is broadly used to reinforce and improve the properties of PMMA. It has been reported that the addition of nano- $\mathrm{ZrO}_{2}$ significantly improved the physical and mechanical properties of $\mathrm{PMMA} / \mathrm{ZrO}{ }_{2}$ nanocomposite. ${ }^{31-33}$ In addition to its biocompatibility, it has an acceptable esthetic, whereby its white color is less likely to alter the look..$^{34,35}$ Slight improvements in the surface properties (increase in hardness and decrease in apparent porosity) were seen by boosting the nano- $\mathrm{ZrO}_{2}$ percentage. ${ }^{36}$ Recently, Gad et $\mathrm{al}^{21}$ studied the effect of nano- $\mathrm{ZrO}_{2}$ on the transverse strength of a repaired denture base and reported a significant increase in transverse strength, especially with high nano- $\mathrm{ZrO}_{2}$ concentrations.

Cold-cured acrylic resin used for repair is mainly used for interim prosthesis fabrication and such prostheses are kept in patients' mouths for $\geq 6$ months. Therefore, the evaluation of nano- $\mathrm{ZrO}_{2}$ addition on Candida was required. Nano- $\mathrm{ZrO}_{2}$ is widely used to improve the physical properties of a PMMA denture base, but its effect on C. albicans to minimize DS has not been investigated. As nano- $\mathrm{ZrO}_{2}$ reinforcement improved the physical properties of a PMMA denture base and a repaired denture base and because it possessed an antimicrobial effect, the hypothesis of this study was that the addition of nano- $\mathrm{ZrO}_{2}$ to cold-cured resin would reduce Candida adhesion. Since poor surface characteristics of repair resin offer an opportunity for further adhesion and colonization of Candida on the denture resin and as the effect of incorporating nano- $\mathrm{ZrO}_{2}$ to repair material on C. albicans has been neglected, this study aimed to assess the effect of the addition of nano- $\mathrm{ZrO}_{2}$ to cold-cured acrylic resin on C. albicans adhesion.

\section{Materials and methods Preparation of heat-polymerized specimens}

A total of 60 rectangular acrylic resin specimens were made using a metal mold with dimensions of $22 \times 10 \times 2.5 \mathrm{~mm}^{3}$ (Figure 1). Specimens' wax-up (Cavex Set Up Wax; Cavex,

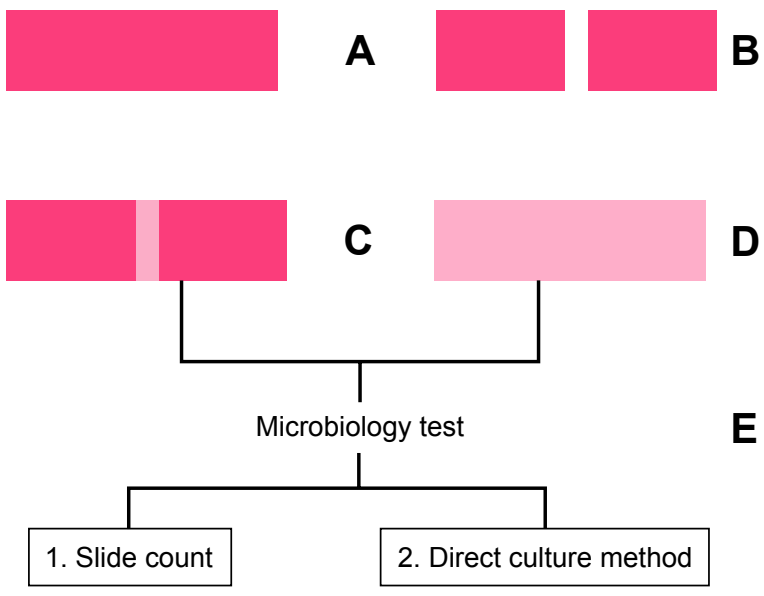

Figure I Workflow of the study specimens' preparation.

Notes: (A) Intact heat polymerized. (B) Sectioned heat polymerized. (C) Repaired heat polymerized represents repaired denture base $(n=60)$. (D) Intact cold-cured acrylic resin represents interim removable prostheses $(n=60)$. (E) Exposed (C) and (D) for microbiology test.

Haarlem, the Netherlands) procedures were performed within the mold and invested using a dental stone (Fujirock EP; GC, Leuven, Belgium) within a flask (61B Two Flask Compress; Handler Manufacturing, Westfield, NJ, USA). The wax was burned out after the complete set of the dental stone. Powder and monomer of heat-polymerized acrylic resin (Major. Base.20, Major Prodotti Dentari SPA, Moncalieri, Italy) were mixed following the manufacturer's instructions and packed in the dough stage into the mold cavity. The flask closure was completed and kept under pressure for $30 \mathrm{~min}$. Acrylic resin specimens were processed for 8 hours in a water bath at $74^{\circ} \mathrm{C}$ followed by 1 hour processing at $100^{\circ} \mathrm{C}$ using a thermal curing unit (KaVo Elektrotechnisches Werk $\mathrm{GmbH}$, Leutkirch, Germany). After polymerization, specimens within flasks were bench cooled prior to deflasking. According to manufacturer's recommendations, finishing and polishing procedures were performed using a tungsten carbide bur (HM251FX-040-HP; Meisinger, Centennial, CO, USA) and acrylic polisher (HM251FX-060; Meisinger) for all specimens' surfaces except for the intaglio surface (tissue-side surface). The intact heat-polymerized acrylic resin specimens were assigned randomly to four groups with 15 repaired specimens each (Table 1).

\section{Repair material preparation}

Nano- $\mathrm{ZrO}_{2}(99.9 \%<100 \mathrm{~nm}, 1314-23-4$; Shanghai Richem International Co., Ltd., Shanghai, China) with a surface area of $9 \pm 2 \mathrm{~m}^{2} / \mathrm{g}$ and an average size of $40 \pm 2 \mathrm{~nm}$ (Figure 2) was treated with $0.3 \mathrm{~g}$ of silane coupling agent 3 -(trimethoxysilyl) propyl methacrylate (TMSPM; Shanghai Richem International Co., Ltd.). This process allows for adequate adhesion between the resin matrix and zirconia nanoparticles. ${ }^{32,34}$ 
Table I Grouping and coding of the specimens according to nano- $\mathrm{ZrO}_{2}$ concentrations

\begin{tabular}{|c|c|c|c|}
\hline Group & Code & Description & No \\
\hline \multirow[t]{4}{*}{$\mathrm{R}$, repair } & RAP & Specimens repaired with pure autopolymerized resin & 15 \\
\hline & $2 \mathrm{RN}$ & Specimens repaired with autopolymerized resin reinforced with $2.5 \%$ wt nano- $\mathrm{ZrO}_{2}$ & 15 \\
\hline & $5 \mathrm{RN}$ & Specimens repaired with autopolymerized resin reinforced with $5 \%$ wt nano- $\mathrm{ZrO}{ }_{2}$ & 15 \\
\hline & $7 R N$ & Specimens repaired with autopolymerized resin reinforced with $7.5 \%$ wt nano- $\mathrm{ZrO}_{2}$ & 15 \\
\hline \multirow[t]{4}{*}{ I, intact } & AP & Intact pure autopolymerized resin & 15 \\
\hline & 2AP & Intact autopolymerized specimen resin reinforced with $2.5 \%$ wt nano- $\mathrm{ZrO}_{2}$ & 15 \\
\hline & $5 \mathrm{AP}$ & Intact autopolymerized specimen resin reinforced with $5 \%$ wt nano- $\mathrm{ZrO}_{2}$ & 15 \\
\hline & 7AP & Intact autopolymerized specimen resin reinforced with $7.5 \%$ wt nano- $\mathrm{ZrO}_{2}$ & 15 \\
\hline
\end{tabular}

Abbreviation: nano- $\mathrm{ZrO}_{2}$, zirconium oxide nanoparticles.

The treated nano- $\mathrm{ZrO}_{2}$ were weighed; prepared in concentrations of $0 \% \mathrm{wt}, 2.5 \% \mathrm{wt}, 5 \% \mathrm{wt}$, or $7.5 \% \mathrm{wt}$ of cold-cured acrylic resin powder (Major.Repair; Major Prodotti Dentari SPA); mixed using a mortar and pestle, and then stirred for $30 \mathrm{~min}$ to achieve an even distribution of particles and to obtain a consistent and uniform color.

\section{Repair procedures}

The heat-polymerized specimens in each of the four groups $(\mathrm{n}=60)$ were sectioned at the center. A line was drawn $1 \mathrm{~mm}$ along and parallel to the cutting edge on both sides. Then, the marked areas were removed using a diamond disk, creating a $2 \mathrm{~mm}$ repair gap. The sectioned parts were assembled into the original mold and fixed to create a $2 \mathrm{~mm}$ repair gap. According to the manufacturer's recommendations, the mixed nanocomposite powder was dispersed in a methyl methacrylate monomer with a powder/liquid mass ratio of $2: 1$; then, the subsequent material was mixed and packed into the repair area, adding an excess amount to compensate for polymerization shrinkage (Table 1). The polymer slightly overfilled the repair gap to compensate for polymerization shrinkage and finishing procedures. Once the surface of the repair material lost its glaze, the molds and their contents were placed in a pressure chamber containing $40^{\circ} \mathrm{C}$ water at a pressure of $30 \mathrm{lb} /$ inch $^{2}$ (pound-force per square inch) for 15 minutes. After polymerization was completed, the specimens were taken out of the molds and excess resins were trimmed. Finishing and polishing procedures were carried out using a tungsten carbide bur (HM251FX-040-HP; Meisinger) and acrylic polisher (HM251FX-060; Meisinger) for all specimens' surfaces except for the intaglio surface (tissue-side surface). Polished specimens were ultrasonically cleaned, placed in distilled water, incubated at $37^{\circ} \mathrm{C}$ for 1 week and then subjected to the microbiology test.

\section{Preparation of intact cold-cured specimens}

A total of 60 standard nano- $\mathrm{ZrO}_{2}$-reinforced cold-cured acrylic resin specimens were prepared in different concentrations of nano- $\mathrm{ZrO}_{2}$ particles (Table 1 and Figure 1D). Nano- $\mathrm{ZrO}_{2}$-reinforced cold-cured acrylic powder was mixed with monomer and packed directly into the molds. Once the
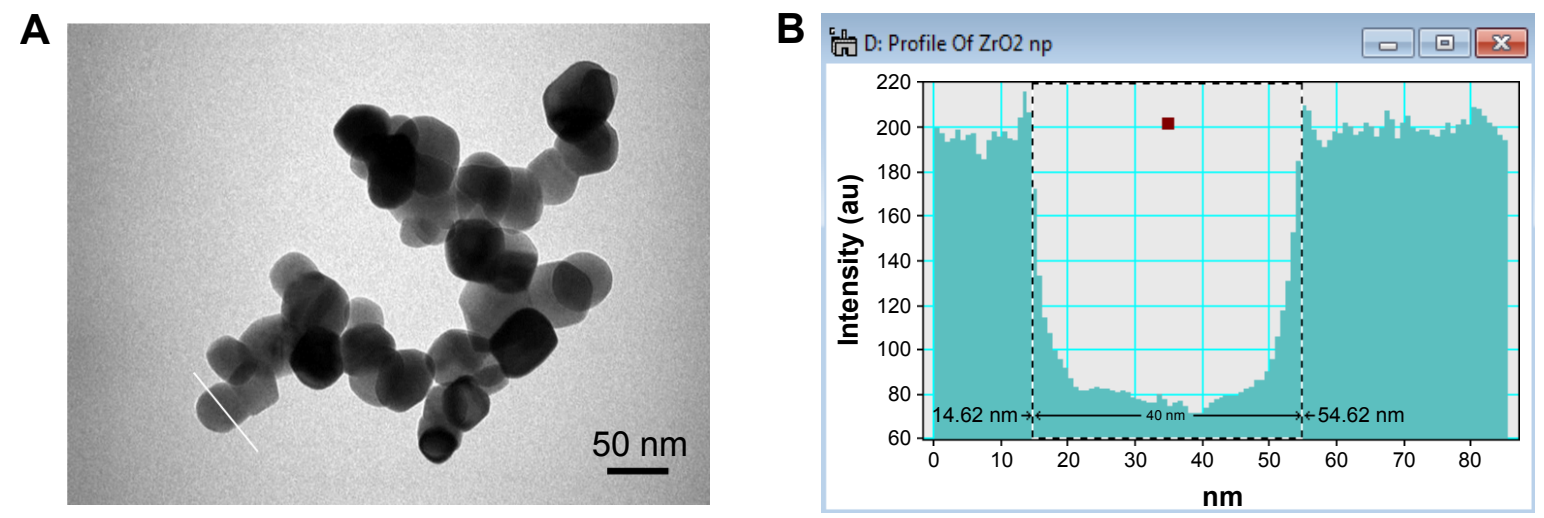

Figure 2 TEM imaging of $\mathrm{ZrO}_{2}$ nanoparticles along with intensity profile.

Notes: (A) TEM image of bunch of nanoparticles. (B) Intensity profile taken from the area shown by a white line in one of the particle in (A). The size of this particle was measured to be $\sim 40 \mathrm{~nm}$. The scale bar corresponds to $50 \mathrm{~nm}$.

Abbreviations: TEM, transmission electron microscopy; au, atomic unit. 
surface of the repair material lost its glaze, the molds and their contents were placed in a pressure chamber containing $40^{\circ} \mathrm{C}$ water at a pressure of $30 \mathrm{lb} / \mathrm{inch}^{2}$ for 15 minutes. After curing, the specimens were removed from the molds, finished, polished (except the intaglio surface) as the repaired group, and subjected to the same microbiology test as the groups of repaired specimens.

\section{Microbiology test}

\section{Exposing acrylic specimens to C. albicans}

All specimens of acrylic plates were immersed in artificial saliva containing 2,000,000 cells of C. albicans (ATCC 10231 ) and then incubated for 48 hours at $37^{\circ} \mathrm{C}$. After that, specimens were washed three times with phosphatebuffered saline, where the number of C. albicans proliferated and attached to the surface of the acrylic resin specimens and were subjected to the evaluation process.

\section{Evaluation}

Two methods were used to calculate the number of living C. albicans adhering to the acrylic resin specimens after the following preparation: plates were incubated for 48 hours in a broth at $37^{\circ} \mathrm{C}$ after washing each specimen with phosphatebuffered saline; they were then vibrated using a vortex, followed by tubes centrifuging with the plates to obtain a concentrated bullet of Candida. At this step, two methods of counting were used for each sample:

1. Slide count: each specimen was placed on a slide counter (Neubauer slide counter with chambers, "Marienfeld") after adding $2.5 \mu \mathrm{L}$ of Trypan Blue $0.4 \%$ solution in phosphate (Mp Biomedical, Santa Ana, CA, USA) to $7.5 \mu \mathrm{L}$ of each sample for microscopic evaluation. Trypan Blue stain was used to differentiate between dead and living C. albicans; living Candida appeared transparent with a blue borderline, while dead C. albicans appeared blue in color. To count the number of Candida, a light microscope at a low power magnification $(10 \times)$ was used. The slide count contained four main squares; each was divided into 16 squares. C. albicans was counted in two main squares and then was multiplied by 2 to estimate the total number of Candida on the slide.

2. Direct culture method: In all, $10 \mu \mathrm{L}$ of each centrifuged bullet was taken and spread on a petri dish. It was then incubated for 24 hours at $37^{\circ} \mathrm{C}$. A marker pen counter (colony counter "SP Scienceware, Bel-Art Products") was used to count the colonies of C. albicans. The numbers of colonies were corrected for the dilution factor. When the numbers of colonies reached $\geq 500$, it was considered overgrowth.

\section{Statistical analysis}

SPSS 20.0 (IBM Corporation, Armonk, NY, USA) was used to run the statistical data analysis. The results of the Candida count with two different methods were represented as arithmetic mean and standard deviation (SD). All variables were checked for normality using the Shapiro-Wilk test. Multivariate analysis of variance (MANOVA) was applied to compare the mean effect on each interval with the baseline in a vertical direction (intragroup) and to compare between two methods in a horizontal direction (intergroup). Post hoc Tukey's HSD test was performed to compare the difference of means between the observations taken at various intervals with the baseline. If the $P$-value was $\leq 0.05$, it was considered as statistically significantly different.

\section{Results MANOVA test}

The mean living Candida counts for all tested specimen groups were statistically significant among the two test methods, the direct culture test and the slide count $(P$-values $<0.0001)$. Table 2 summarizes the MANOVA test findings across the culture count and slide count methods. The mean difference between the two tested methods regarding the number of living C. albicans is illustrated in Figures 3 and 4.

\section{Direct culture method}

A culture test was also performed to count the number of living Candida (Figures 3 and 4), and an SD at 95\% CI was calculated for each group. Variations of living Candida for each group, compared with the baseline group, were checked for statistical significance in a linear manner. An analysis of variance (ANOVA) test was used that found that, for baseline repaired specimens, the mean living Candida count was significantly higher than all tested groups following the

Table 2 Mean, SD, and MANOVA test results of live Candida count for both test methods

\begin{tabular}{llllll}
\hline Code & $\begin{array}{l}\text { Culture count } \\
(\text { mean } \pm \text { SD) }\end{array}$ & $\begin{array}{l}\text { Slide count } \\
(\text { mean } \pm \text { SD) }\end{array}$ & n & F & P-value \\
\hline RAP & $782.00 \pm \mid 4.407$ & $704.30 \pm I 2.859$ & 15 & 161.9 & $<0.000 I^{*}$ \\
2RN & $462.40 \pm 10.617$ & $500.20 \pm I 1.084$ & 15 & 60.66 & $<0.000 I^{*}$ \\
5RN & $429.70 \pm 7.056$ & $498.40 \pm 8.140$ & 15 & 406.7 & $<0.000 I^{*}$ \\
$7 R N$ & $401.60 \pm 8.181$ & $497.40 \pm 6.077$ & 15 & 883.6 & $<0.000 I^{*}$ \\
AP & $676.40 \pm 15.364$ & $732.40 \pm 11.530$ & 15 & 85.0 & $<0.000 I^{*}$ \\
2AP & $597.30 \pm 10.935$ & $573.70 \pm 10.350$ & 15 & 24.6 & $<0.000 I^{*}$ \\
5AP & $446.90 \pm 10.713$ & $320.10 \pm 16.408$ & 15 & 418.7 & $<0.000 I^{*}$ \\
7AP & $355.10 \pm 40.289$ & $269.00 \pm 9.752$ & 15 & 43.1 & $<0.000 I^{*}$ \\
\hline
\end{tabular}

Notes: *Significant difference among the observations taken on various intervals compared to the baseline at $\alpha=0.0$ I level of significance. Description of the groups is presented in Table I.

Abbreviations: SD, standard deviation; MANOVA, multivariate analysis of variance. 

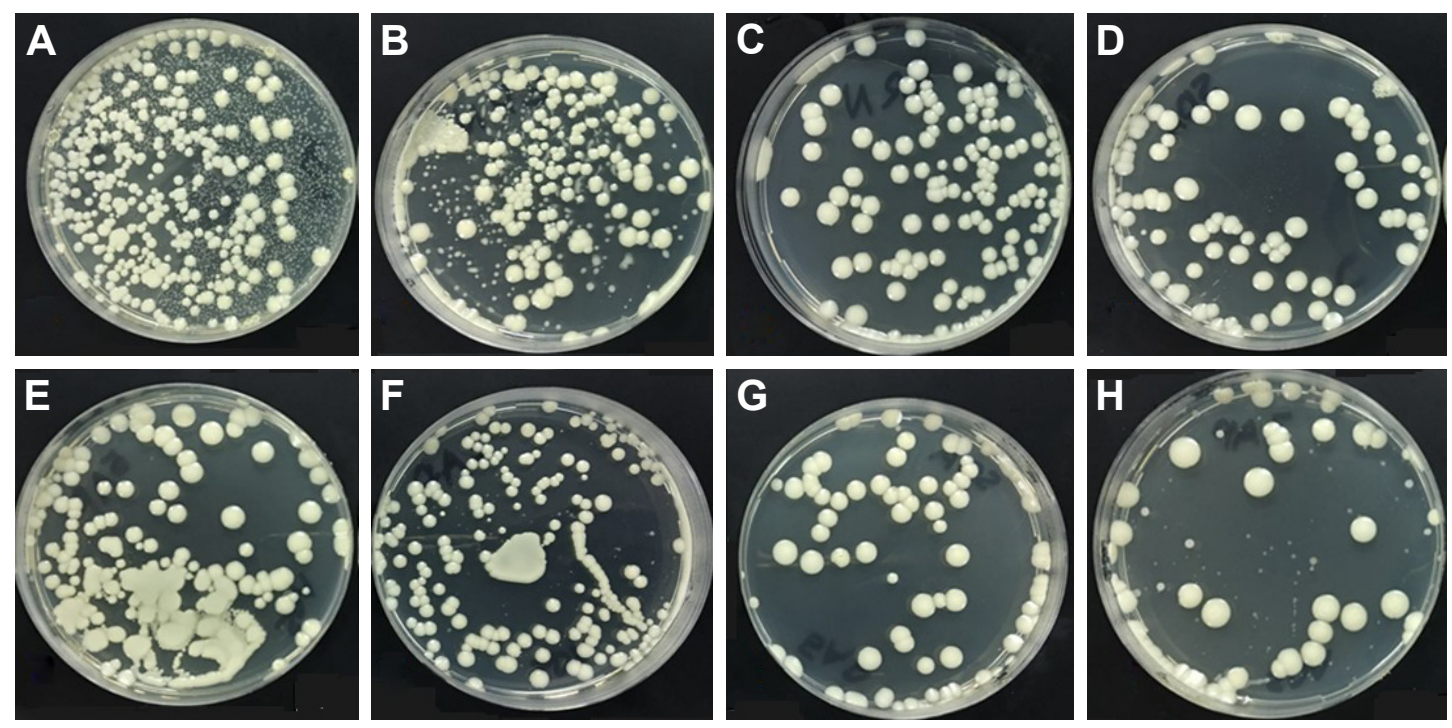

Figure 3 Culture count of repair and intact groups with different concentrations of nano- $\mathrm{ZrO}$ and colonies of Candida.

Notes: (A-D) Repair material reinforced with $0 \%, 2.5 \%, 5 \%$, and $7.5 \%$, respectively. (E-H) Intact cold-cured acrylic resin reinforced with $0 \%, 2.5 \%$, $5 \%$, and $7.5 \%$, respectively.

Abbreviation: nano- $\mathrm{ZrO}_{2}$, zirconium oxide nanoparticles.

addition of nano- $\mathrm{ZrO}_{2}$ fillers. As the concentration of nano$\mathrm{ZrO}_{2}$ increased, the Candida count significantly decreased in comparison with RAP ( $P$-values $<0.001)$. $7 \mathrm{RN}$ had the lowest living Candida counts among their designated groups with a mean value of 401.6. Table 3 summarizes the ANOVA findings for the repaired specimens. Similarly, the intact cold-cured groups showed a significant difference between the unreinforced intact cold-cured groups and nano- $\mathrm{ZrO}_{2}-$ reinforced groups $(P$-values $<0.01)$. Once again, the mean

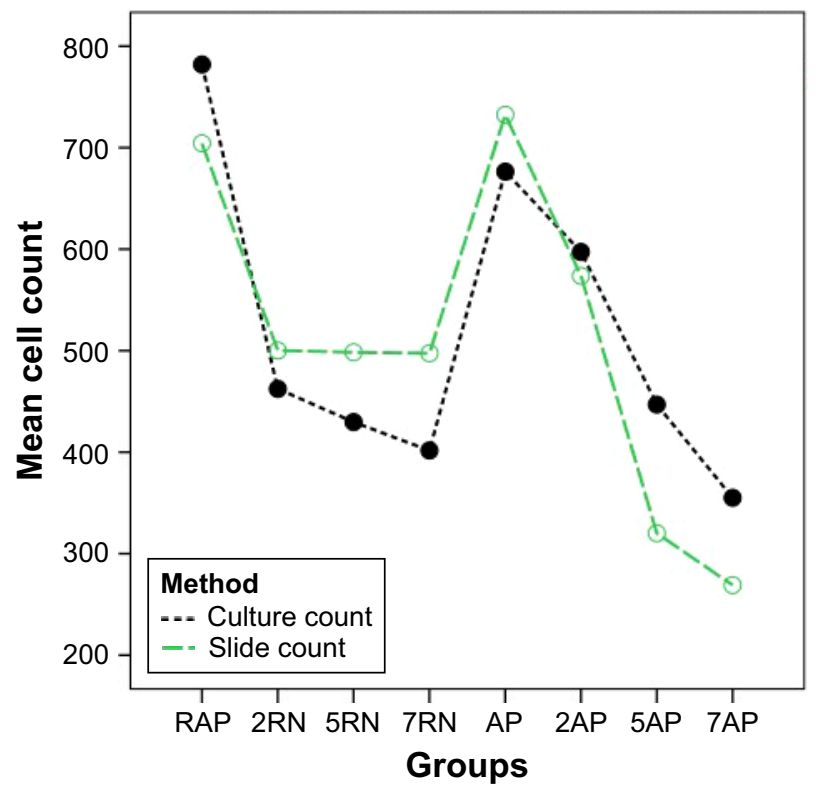

Figure 4 Comparison of mean cell count between two methods. Note: Description of the groups is presented in Table I. living Candida count significantly decreased as nano- $\mathrm{ZrO}_{2}$ concentrations increased. 7AP showed the lowest living $\mathrm{Can}$ dida count with a mean value of 355.1. Table 4 summarizes the ANOVA findings for the intact cold-cured specimens using the direct culture method. To further analyze the differences between the groups, a post hoc analysis found that all groups were significantly different using the culture count method ( $P$-values $<0.01)$.

\section{Slide count}

Using the light microscope, it was shown that the mean numbers of counted living C. albicans for baseline groups were significantly higher than those for the nano- $\mathrm{ZrO}_{2}$-reinforced groups. Within the repaired groups, RAP, $2 \mathrm{RN}, 5 \mathrm{RN}$, and $7 \mathrm{RN}$, a statistically significant difference was observed $(P$-values $<0.01)$. The post hoc analysis revealed that only the baseline RAP group was significantly different from the other groups $(P$-values $<0.01)$. However, the $2 \mathrm{RN}, 5 \mathrm{RN}$, and 7RN groups were not statistically different. Table 3 summarizes the ANOVA and post hoc findings for the repaired specimens using the slide count method. Among the intact cold-cured group, it was found that this variation in living Candida between the unreinforced group and the nano- $\mathrm{ZrO}_{2}$-reinforced group was significantly different ( $P$-values $<0.01)$. As the concentrations of nano- $\mathrm{ZrO}_{2}$ increased, the mean slide count of Candida decreased. The differences between the groups were statistically significant $(P$-values $<0.01)$. The 7AP group had the lowest 
Table 3 ANOVA test for association between live Candida count for both test methods and the percentage of $\mathrm{ZrO}_{2}$ by weight for RN

\begin{tabular}{|c|c|c|c|c|c|c|c|}
\hline Variable & Mean \pm SD & $95 \% \mathrm{Cl}$ & & $F$ & $\begin{array}{l}\text { ANOVA, } \\
\text { P-value }\end{array}$ & $\begin{array}{l}\text { Comparison } \\
\text { group }\end{array}$ & Post hoc \\
\hline Culture count & & & & $4,308.02$ & $<0.00 I^{*}$ & & \\
\hline RAP & $782.00 \pm 14.407$ & 771.7 & 792.3 & & & RAP vs 2 RN & $0.005^{*}$ \\
\hline \multirow[t]{2}{*}{$2 \mathrm{RN}$} & $462.40 \pm 10.617$ & 454.8 & 470.0 & & & RAP vs $5 R N$ & $0.005^{*}$ \\
\hline & & & & & & RAP vs $7 R N$ & $0.005 *$ \\
\hline \multirow[t]{2}{*}{$5 \mathrm{RN}$} & $429.70 \pm 7.056$ & 424.7 & 434.7 & & & $2 \mathrm{RN}$ vs $5 \mathrm{RN}$ & $0.005^{*}$ \\
\hline & & & & & & $2 R N$ vs $7 R N$ & $0.005^{*}$ \\
\hline $7 R N$ & $401.60 \pm 8.181$ & 395.7 & 407.4 & & & $5 R N$ vs $7 R N$ & $0.005^{*}$ \\
\hline Slide count & & & & $\mathrm{I}, 620.74$ & $<0.00 I^{*}$ & & \\
\hline RAP & $704.30 \pm 12.859$ & 695.1 & 713.5 & & & RAP vs 2 RN & $0.005^{*}$ \\
\hline \multirow[t]{2}{*}{$2 \mathrm{RN}$} & $500.20 \pm 11.084$ & 492.3 & 508.1 & & & RAP vs $5 R N$ & $0.005^{*}$ \\
\hline & & & & & & RAP vs $7 R N$ & $0.005^{*}$ \\
\hline \multirow[t]{2}{*}{$5 \mathrm{RN}$} & $498.40 \pm 8.140$ & 492.6 & 504.2 & & & $2 R N$ vs $5 R N$ & $0.859 *$ \\
\hline & & & & & & $2 R N$ vs $7 R N$ & $0.415^{*}$ \\
\hline $7 R N$ & $497.40 \pm 6.077$ & 493.1 & 501.7 & & & $5 R N$ vs $7 R N$ & $0.574^{*}$ \\
\hline
\end{tabular}

Notes: All tests were performed at a significance level of $\alpha=0.05$. *Significant at $P<0.01$. Description of the groups is presented in Table 1 .

Abbreviations: SD, standard deviation; ANOVA, analysis of variance.

mean Candida count value at 269. Table 4 summarizes the ANOVA findings for the intact cold-cured specimens using the culture count.

\section{Transmission electron microscopy (TEM) results of nano- $\mathrm{ZrO} 2$}

TEM was performed to estimate the size of nano- $\mathrm{ZrO}_{2}$ (Figure 1A). Several such images were taken to measure the average size of the particles. The size of different particles was measured by extracting the intensity profiles as shown in Figure 1B. This intensity profile was taken from the area (having a particle) shown by a white line. The size of this particle was measured to be $\sim 40 \mathrm{~nm}$. The average size of the particle was estimated to be $\sim 40 \pm 2 \mathrm{~nm}$ and the SD to be $\sim 11 \mathrm{~nm}$. In all, $>80$ particles were taken for this measurement.

\section{Scanning electron microscopy (SEM) for specimen surface analysis}

SEM analyses showed high surface roughness in unreinforced cold-cured acrylic resin (Figure 5A and C), while the addition of nano- $\mathrm{ZrO}_{2}$ exhibited smooth surface in addition to the presence of nanoparticles on the resin surfaces (Figure 5B and D).

Table 4 ANOVA test for association between live Candida count for both test methods and the percentage of $\mathrm{ZrO}_{2}$ by weight for AP

\begin{tabular}{|c|c|c|c|c|c|c|c|}
\hline Variable & Mean \pm SD & $95 \% \mathrm{Cl}$ & & $\boldsymbol{F}$ & $\begin{array}{l}\text { ANOVA, } \\
\text { P-value }\end{array}$ & $\begin{array}{l}\text { Comparison } \\
\text { group }\end{array}$ & Post hoc \\
\hline Culture count & & & & 601.52 & $0.001 *$ & & \\
\hline AP & $676.40 \pm 15.364$ & 665.4 & 687.4 & & & AP vs $2 A P$ & $0.005^{*}$ \\
\hline \multirow[t]{2}{*}{$2 \mathrm{AP}$} & $597.30 \pm 10.935$ & 589.5 & 605.1 & & & AP vs $5 A P$ & $0.005^{*}$ \\
\hline & & & & & & AP vs 7AP & $0.005^{*}$ \\
\hline \multirow[t]{2}{*}{$5 A P$} & $446.90 \pm 10.713$ & 439.2 & 454.6 & & & $2 A P$ vs $5 A P$ & $0.005^{*}$ \\
\hline & & & & & & $2 A P$ vs $7 A P$ & $0.005^{*}$ \\
\hline 7AP & $355.10 \pm 40.289$ & 383.9 & 383.9 & & & $5 A P$ vs $7 A P$ & $0.007 *$ \\
\hline Slide count & & & & $4,712.9$ & $0.001 *$ & & \\
\hline $\mathrm{AP}$ & $732.40 \pm 11.530$ & 724.1 & 740.6 & & & AP vs $2 A P$ & $0.005^{*}$ \\
\hline $2 \mathrm{AP}$ & $573.70 \pm 10.350$ & 566.3 & 581.1 & & & AP vs $5 A P$ & $0.005^{*}$ \\
\hline \multirow[t]{2}{*}{$5 \mathrm{AP}$} & $320.10 \pm 16.408$ & 308.4 & 331.8 & & & AP vs 7AP & $0.005^{*}$ \\
\hline & $269.00 \pm 9.752$ & 262.0 & 276.0 & & & $2 \mathrm{AP}$ vs $5 \mathrm{AP}$ & $0.005^{*}$ \\
\hline \multirow[t]{2}{*}{ 7AP } & & & & & & $2 A P$ vs $7 A P$ & $0.005^{*}$ \\
\hline & & & & & & $5 A P$ vs $7 A P$ & $0.005^{*}$ \\
\hline
\end{tabular}

Notes: All tests were performed at a significance level of $\alpha=0.05$. *Significant at $P<0.01$. Description of the groups is presented in Table I.

Abbreviations: ANOVA, analysis of variance; SD, standard deviation. 

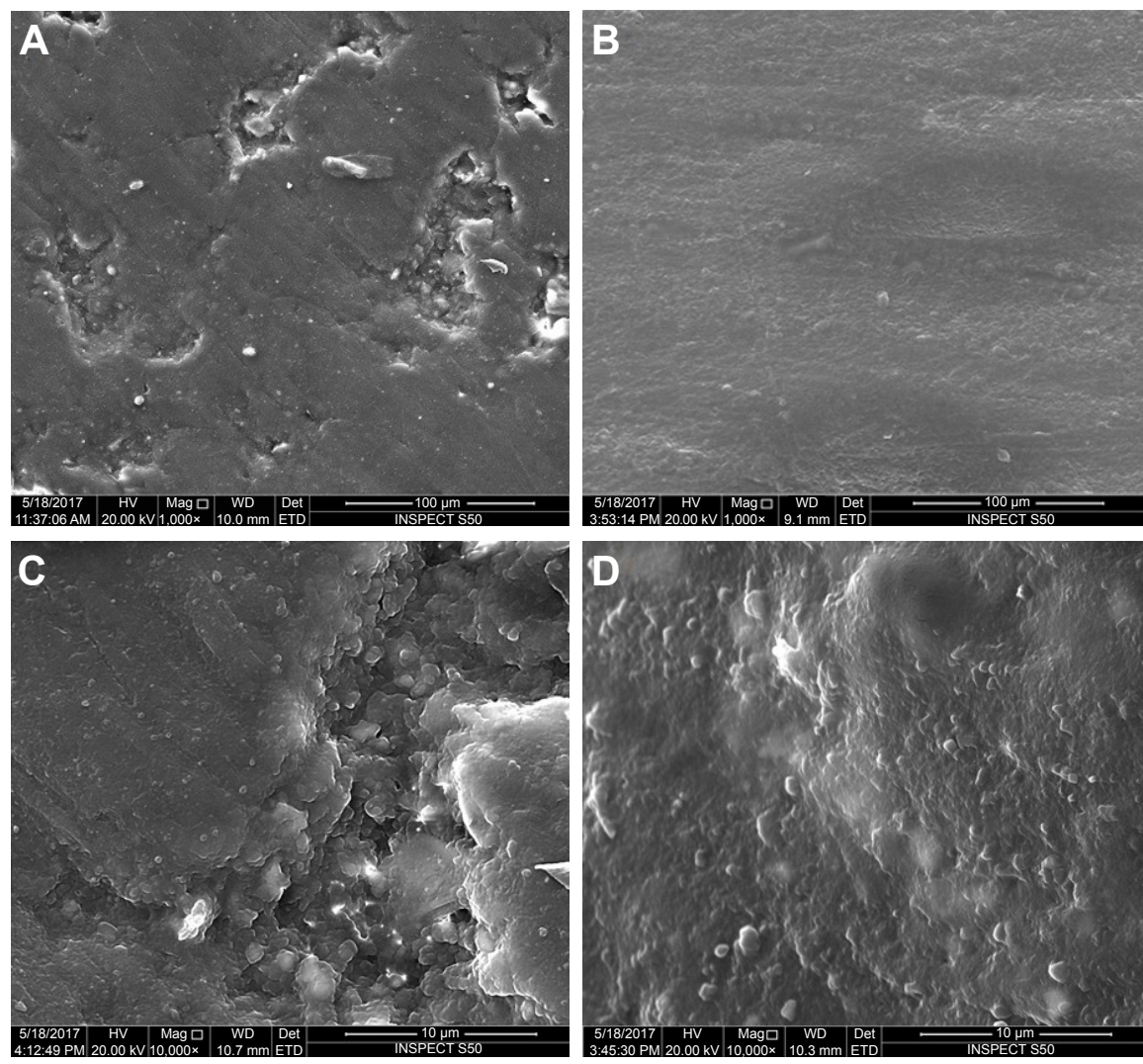

Figure 5 Representative SEM images for cold-cured acrylic resin specimens.

Notes: (A) Cold-cured acrylic resin without nano- $\mathrm{ZrO}_{2}$ (low magnification, I,000x), (B) cold-cured acrylic resin with nano- $\mathrm{ZrO}{ }_{2}$ (low magnification, I,000x), (C) cold-cured acrylic resin without nano- $\mathrm{ZrO}_{2}$ (high magnification, $10,000 \times$ ), and (D) cold-cured acrylic resin with nano- $\mathrm{ZrO}_{2}$ (high magnification, $10,000 \times$ ).

Abbreviations: SEM, scanning electron microscopy; nano- $\mathrm{ZrO}_{2}$, zirconium oxide nanoparticles.

\section{Discussion}

Cold-cured acrylic resin has been included in the fabrication of interim removable prostheses, orthodontic appliances, and also for repairing broken denture bases. ${ }^{12,15}$ Therefore, the investigation of nano- $\mathrm{ZrO}_{2}$ effect on C. albicans adhesion is essential. This study was conducted using cold-cured acrylic resin as a repair material (repair group), which could affect the mechanical behavior of denture repair and its ability to provide antifungal activity, while the other intact cold-cured group was used for removable prosthesis fabrication. Therefore, from a clinical perspective, the results of the current study supported that nano- $\mathrm{ZrO}_{2}$-reinforced cold-cured acrylic resin could be used as a valuable treatment protocol in two ways: as a repair material and as a material used in the fabrication of removable interim dentures and orthodontic appliances.

Prevention of DS could be achieved by preventing or at least reducing Candida adhesion to denture surfaces. ${ }^{37}$ Therefore, more research related to denture materials and focusing on ways to reduce the adhesion of biofilms are needed. Such research may be effective in decreasing yeast and bacterial colonization, which could assist in the potential reduction in DS. ${ }^{8}$ Many studies have investigated the role of modified denture surfaces in decreasing the adhesion of C. albicans and minimizing the formulation of biofilms on denture surfaces. ${ }^{8,10,11,20,38}$ Most of the previous studies concentrated on polishing and smoothing the different denture base materials and adding antimicrobial reinforcement material, such as nanosilver. ${ }^{19,31,39}$ However, the antibacterial impact of zirconia nanoparticles (nano- $\mathrm{ZrO}_{2}$ ) against C. albicans has not been well addressed. Therefore, the current study was conducted to assess the antifungal effect of nano- $\mathrm{ZrO}_{2}$ on the adhesion of $C$. albicans to acrylic resin denture bases repaired with nano- $\mathrm{ZrO}_{2}$-reinforced cold-cured acrylic resin and denture bases made of cold-cured acrylic resins.

It was found that nano- $\mathrm{ZrO}_{2}$ could have an antifungal effect on both the repaired denture base and intact coldcured resins. The significant difference in the reduction of the number of $C$. albicans was observed with the addition of $7.5 \%$ nano- $\mathrm{ZrO}_{2}$ using both tested methods. This result indicated that nano- $\mathrm{ZrO}_{2}$ can be an effective material in the creation of an antimicrobial medium against $C$. albicans. Therefore, the hypothesis of this study was supported. 
It has been accepted that repairing a fractured denture base depends on many variables, such as denture base resin combination, repair material, surface design, and the treatment or technique used..$^{40}$ Therefore, the microstructure and surface texture of the repair material would not look or function as the original denture base material. The adhesion of Candida is related to the existence of the microporosity of the denture surface, ${ }^{41}$ and if such a condition occurs, Candida species can easily proliferate. Even though there are many ways to repair dentures, cold-cured acrylic resins provide a simple and quick application that is still the selection of choice to repair a fractured or cracked denture base material.

In the current study, the mean number of colonies of C. albicans in the tested groups decreased compared with the control group. These drawbacks of cold polymerization may be explained by the chemical initiator that reduces the conversion degree during the polymerization stage and disrupts the surface structure. ${ }^{20,40,42}$ These statements are consistent with the results of the current study that the coldcured group represented high colony numbers. This may be due to the surface roughness of this repairing material. It is well known that microbial adherence is highly affected by surface roughness. ${ }^{19}$ Basically, resin roughness and voids in the fitting surface of denture base acrylic enhance the initial microbial adhesion. ${ }^{43}$

The findings of the present study indicated that repair acrylic resin reinforced with nano- $\mathrm{ZrO}_{2}$ significantly reduced the microbial counts. The addition of nano- $\mathrm{ZrO}_{2}$ to repair resin resulted in a significant decrease in C. albicans count, and the maximum decrease was found with the addition of $7.5 \%$ of nano- $\mathrm{ZrO}_{2}$. This decrease in the colony number may be attributed to the antimicrobial activity of nano- $\mathrm{ZrO}_{2}$ or its potential effect in improving surface properties. The antimicrobial effect of nano- $\mathrm{ZrO}_{2}$ was reported by Jangra et $\mathrm{al}^{29}$ who found that nano- $\mathrm{ZrO}{ }_{2}$ worked preliminarily on the bacterial strains of $E$. coli and $S$. aureus and on the fungal strain of $A$. niger and mainly showed activity against only E. coli. ${ }^{36}$ Some studies showed that nano- $\mathrm{ZrO}_{2}$ fills polymeric chain spaces and spaces on the surface, as its proper bonding to the polymer matrix resulted in smooth surfaces, which could prevent $C$. albicans adhesion. ${ }^{36,44}$ Owing to the double effect of nano- $\mathrm{ZrO}_{2}$ (antimicrobial and surface texture changes; Figure 5B and D), this investigation might have an impact in minimizing the adhesion of C. albicans in relation to DS development.

In agreement with the findings of Gowri et al, ${ }^{28}$ nano$\mathrm{ZrO}_{2}$ in this study almost showed significant inhibition effect against fungal strains. Nano- $\mathrm{ZrO}_{2}$ may actively inhibit the growth of fungal strains by interfering in cell function and causing deformation in fungal hyphae..$^{28}$ Another explanation could be that the differences in antibacterial activity of nano- $\mathrm{ZrO}_{2}$ against $S$. aureus and $E$. coli could be attributed to the surface charge. Generally, it is believed that chemical reactivation of crystals may be significantly affected by their shapes, due to the surface energy, surface atom arrangement, and bonding. ${ }^{27}$ Different atomic planes have different surface energies, where the density of the dangling bonds on the surface dominates the contribution to the surface energy of nanostructures. This difference in surface energy plays a crucial role in defining the antibacterial and antifungal properties of nanostructured inorganic materials. ${ }^{45,46}$ Additionally, it could be speculated that the nano- $\mathrm{ZrO}_{2}$ has the same surface geometry, but with different shapes, different active facets may exhibit different antimicrobial activities. ${ }^{29}$

Based on the results of the current study, significant differences were found between reinforced cold-cured acrylic resin and the control group. Moreover, significant differences were found between reinforced cold-cured acrylic resin as nano- $\mathrm{ZrO}_{2}$ concentration increased, which confirmed the potential effect of nano- $\mathrm{ZrO}_{2}$ in the prevention of Candida adhesion (Figure 3).

In comparing the repair and intact cold-cured groups, the intact groups demonstrated fewer colony numbers with the same percentage of nano- $\mathrm{ZrO}_{2}$. This finding raised another factor that could affect Candida adhesions and that may be related to different resin types or the joints between the denture base and repair resin. These joints may act as a reservoir for C. albicans, particularly if they are not prepared properly.

The limitations of this study included the evaluation of one repair material method in vitro. The test conditions were not similar to those of the oral cavity, and no aging procedure was performed. On the other hand, the oral environment usually consists of several microorganisms, not only C. albicans. In future studies, under better simulated conditions, varied microorganisms and even biofilm formations should be evaluated.

From a clinical point of view, the results of this study have been interpreted with caution because the environment of the oral cavity is dynamic. Multiple factors, including $\mathrm{pH}$, the presence of different microorganisms, and saliva, can affect the microbial adhesion to the denture surface. ${ }^{41,47}$ Clinical implications of this study include that nano- $\mathrm{ZrO}_{2}$ could be added to repair resin due to its potential effect on reducing and preventing adhesion and proliferation of Candida. Additionally, cold-cured removable prostheses could be fabricated 
with the addition of nano- $\mathrm{ZrO}_{2}$. Moreover, the addition of nano- $\mathrm{ZrO}_{2}$ to an acrylic denture base could increase the antifungal activity while maintaining adequate mechanical properties for clinical use. Therefore, further investigation into the antifungal effect of denture base material reinforced with nano- $\mathrm{ZrO}_{2}$ is required. Moreover, the durability of these nanocomposites is of importance, because it could help complete-denture wearers who have restricted manual proficiency or cognitive disorders to improve their denture hygiene status.

\section{Conclusion}

Within the limitations of this study, we can conclude that repair acrylic resin modified with nano- $\mathrm{ZrO}_{2}$ could exhibit antifungal effects on $C$. albicans and could be used for the prevention of DS by preventing Candida adhesion. Adding zirconia nanoparticles to cold-cured resin could be an effective method to reduce the adhesion of $C$. albicans on surfaces of PMMA interim prostheses. However, further investigation into its durability is still required.

\section{Acknowledgments}

The authors would like to thank the Deanship of Scientific Research, University of Dammam, for providing a research grant for this study (Grant No 2014142). The authors would like to deeply thank Dr Lindsey Mateo and Mr Intisar Siddiqui for their assistance with the mechanical testing and statistical analysis.

\section{Disclosure}

The authors report no conflicts of interest in this work.

\section{References}

1. Zomorodian K, Haghighi NN, Rajaee N, et al. Assessment of Candida species colonization and denture-related stomatitis in complete denture wearers. Med Mycol. 2011;49(2):208-211.

2. Pattanaik S. Denture stomatitis: a literature review. J Indian Acad Oral Med Radiol. 2010;22(3):136-140.

3. Budtz-Jorgensen E. Oral mucosal lesions associated with the wearing of removable dentures. J Oral Pathol. 1981;10(2):65-80.

4. Vasilas A, Molina L, Hoffman M, Haidaris CG. The influence of morphological variation on Candida albicans adhesion to denture acrylic in vitro. Arch Oral Biol. 1992;37(8):613-622.

5. Barbeau J, Seguin J, Goulet JP, et al. Reassessing the presence of Candida albicans in denture-related stomatitis. Oral Surg Oral Med Oral Pathol Oral Radiol Endod. 2003;95(1):51-59.

6. Dills SS, Olshan AM, Goldner S, Brogdon C. Comparison of the antimicrobial capability of an abrasive paste and chemical-soak denture cleaners. J Prosthet Dent. 1988;60(4):467-470.

7. Izumida FE, Moffa EB, Vergani CE, Machado AL, Jorge JH, GiampaoloET. In vitro evaluation of adherence of Candida albicans, Candida glabrata, and Streptococcus mutans to an acrylic resin modified by experimental coatings. Biofouling. 2014;30(5):525-533.
8. Ali AA, Alharbi FA, Suresh CS. Effectiveness of coating acrylic resin dentures on the Candida adhesion. J Prosthodont. 2013;22(6):445-450.

9. Yodmongkol S, Chantarachindawong R, Thaweboon S, Thaweboon B, Amornsakchai T, Srikhirin T. The effects of silane- $\mathrm{SiO}_{2}$ nanocomposite films on Candida albicans adhesion and the surface and physical properties of acrylic resin denture base material. J Prosthet Dent. 2014; 112(6):1530-1538.

10. Queiroz JC, Fissmer SF, Koga-Ito CY, et al. Effect of diamond-like carbon thin film coated acrylic resin on Candida albicans biofilm formation. J Prosthodont. 2013;22(6):451-455.

11. Nawasrah A, AlNimr A, Ali AA. Antifungal effect of henna against Candida albicans adhered to acrylic resin as a possible method for prevention of denture stomatitis. Int J Environ Res Public Health. 2016; 13(5):520.

12. Faot F, da Silva WJ, da Rosa RS, Del Bel Cury AA, Garcia RC. Strength of denture base resins repaired with auto- and visible light-polymerized materials. J Prosthodont. 2009;18(6):496-502.

13. Beyli MS, von Fraunhofer JA. Repair of fractured acrylic resin. J Prosthet Dent. 1980;44(5):497-503.

14. Polyzois GL, Handley RW, Stafford GD. Repair strength of denture base resins using various methods. Eur J Prosthodont Restor Dent. 1995; 34(4):183-186.

15. Alkurt M, Yeşil Duymuş Z, Gundogdu M. Effect of repair resin type and surface treatment on the repair strength of heat-polymerized denture base resin. J Prosthet Dent. 2014;111(1):71-78.

16. Beyli MS, von Fraunhofer JA. An analysis of causes of fracture of acrylic resin dentures. J Prosthet Dent. 1981;46(3):238-241.

17. ArioliFilho JN, Butignon LE, Pereira Rde P, Lucas MG, MolloFde AJ. Flexural strength of acrylic resin repairs processed by different methods: water bath, microwave energy and chemical polymerization. $J$ Appl Oral Sci. 2011;19(3):249-253.

18. Kulak Y, Arikan A, Kazazoglu E. Existence of Candida albicans and microorganisms in denture stomatitis patients. J Oral Rehabil. 1997; 24(10):788-790.

19. Radford DR, Sweet SP, Challacombe SJ, Walter JD. Adherence of Candida albicans to denture-base materials with different surface finishes. J Dent. 1998;26(7):577-583.

20. Şahin C, Ergin A, Ayyıldız S, Uzun G. Evaluation of flexural strength and Candida albicans adhesion of an acrylic resin repaired with 4 different resin materials. Clin Dent Res. 2012;36(2):10-14.

21. Gad M, ArRejaie AS, Abdel-Halim MS, Rahoma A. The reinforcement effect of nano-zirconia on the transverse strength of repaired acrylic denture base. Int J Dent. 2016;2016:6.

22. Ferro KJ, Morgano SM, Driscoll CF, et al. The glossary of prosthodontic terms. Ninth edition. The academy of prosthodontics. J Prosthet Dent. 2017;117:1-105.

23. Higginbottom F, Belser U, Jones J, Keith S. Prosthetic management of implants in the esthetic zone. Int J Oral Maxillofac Implants. 2004; 19(suppl):62-72.

24. Al-Thobity AM. Fabrication of an implant-supported fixed interim prosthesis using a duplicate denture: an alternative technique. J Prosthodont. Epub 2016.

25. Alfonso C, Toothacker RW, Wright RF, White GS. A technique to create appropriate abutment tooth contours for removable partial dentures. J Prosthodont. 1999;8(4):273-275.

26. Gu FX, Karnik R, Wang AZ, et al. Targeted nanoparticles for cancer therapy. Nano Today. 2007;3:14-21.

27. Wang X, Wu HF, Kuang Q, Huang RB, Xie ZX, Zheng LS. Shape-dependent antibacterial activities of $\mathrm{Ag}_{2} \mathrm{O}$ polyhedral particles. Langmuir. 2010;26(4):2774-2778.

28. Gowri S, Rajiv Gandhi R, Sundrarajan M. Structural, optical, antibacterial and antifungal properties of zirconia nanoparticles by biobased protocol. J Mater Sci Technol. 2014;30(8):782-790.

29. Jangra SL, Stalin L, Dilbaghi N, et al. Antimicrobial activity of zirconia $\left(\mathrm{ZrO}_{2}\right)$ nanoparticles and zirconium complexes. J Nanosci Nanotechnol. 2012;12(9):7105-7112. 
30. Veeraapandian S, Sawant SN, Doble M. Antibacterial and antioxidant activity of protein capped silver and gold nanoparticles synthesized with Escherichia coli. J Biomed Nanotechnol. 2012;8(1):140-148.

31. Gad MM, Fouda SM, Al-Harbi FA, Näpänkangas R, Raustia A. PMMA denture base material enhancement: a review of fiber, filler, and nanofiller addition. Int J Nanomedicine. 2017;12:3801-3812.

32. Ayad NM, Badawi MF, Fatah AA. Effect of reinforcement of highimpact acrylic resin with zirconia on some physical and mechanical properties. Rev Cl'n Pesq Odontol. 2008;4(3):145-151.

33. Gad MM, Rahoma A, Al-Thobity AM, ArRejaie AS. Influence of incorporation of $\mathrm{ZrO}_{2}$ nanoparticles on the repair strength of polymethyl methacrylate denture bases. Int J Nanomedicine. 2016;11:5633-5643.

34. Mallineni SK, Nuvvula S, Matinlinna JP, Yiu CK, King NM. Biocompatibility of various dental materials in contemporary dentistry: a narrative insight. J Investig Clin Dent. 2013;4(1):9-19.

35. Seabra AB, Durán N. Nanotoxicology of metal oxide nanoparticles. Metals. 2015;5(2):934-975.

36. Hameed HK, Abdul Rahman $\mathrm{H}$. The effect of addition nanoparticle $\mathrm{ZrO}_{2}$ on some properties of autoclave processed heat cures acrylic denture base material. J Bagh Coll Dent. 2015;27(1):32-39.

37. Gendreau L, Loewy Z. Epidemiology and etiology of denture stomatitis. J Prosthodont. 2011;20(4):251-260.

38. von Fraunhofer JA, Loewy ZG. Factors involved in microbial colonization of oral prostheses. Gen Dent. 2009;57(2):136-143.

39. Ki-Young N, Cheong-Hee L, Chul-Jae L. Antifungal and physical characteristics of modified denture base acrylic incorporated with silver nanoparticles. Gerodontology. 2012;29(2):e413-e419.
40. Seo RS, Neppelenbroek KH, Filho JN. Factors affecting the strength of denture repairs. J Prosthodont. 2007;16(4):302-310.

41. Ferreira MA, Pereira-Cenci T, Rodrigues LM, Rodrigues-Garcia RC, Del Bel Cury AA. Efficacy of denture cleansers on denture liners contaminated with Candida species. Clin Oral Investig. 2009;13(2):237-242.

42. Vallittu PK. The effect of surface treatment of denture acrylic resin on the residual monomer content and its release into water. Acta Odontol Scand. 1996;54(3):188-192.

43. Matsuura T, Abe Y, Sato Y, Okamoto K, Ueshige M, Akagawa Y. Prolonged antimicrobial effect of tissue conditioners containing silverzeolite. J Dent. 1997;25(5):373-377.

44. Ihab NS, Moudhaffar M. Evaluation the effect of modified nano-fillers addition on some properties of heat cured acrylic denture base material. J Bagh Coll Dent. 2011;23:23-29.

45. Wang X, Yang F, Yang W, Yang X. A study on the antibacterial activity of one-dimensional $\mathrm{ZnO}$ nanowire arrays: effects of the orientation and plane surface. Chem Commun (Camb). 2007;42:4419-4421.

46. Park SE, Blissett R, Susarla SM, Weber HP. Candida albicans adherence to surface-modified denture resin surfaces. J Prosthodont. 2008; 17(5):365-369.

47. Al-Thobity AM, Al-Khalifa KS, Gad MM, Al-Hariri M, Ali AA, Alnassar T. In vitro evaluation of the inhibitory activity of thymoquinone in combatting candida albicans in denture stomatitis prevention. Int J Environ Res Public Health. 2017;14(7):743.
International Journal of Nanomedicine

\section{Publish your work in this journal}

The International Journal of Nanomedicine is an international, peerreviewed journal focusing on the application of nanotechnology in diagnostics, therapeutics, and drug delivery systems throughou the biomedical field. This journal is indexed on PubMed Central, MedLine, CAS, SciSearch $\AA$, Current Contents $₫ /$ Clinical Medicine,

\section{Dovepress}

Journal Citation Reports/Science Edition, EMBase, Scopus and the Elsevier Bibliographic databases. The manuscript management system is completely online and includes a very quick and fair peer-review system, which is all easy to use. Visit http://www.dovepress.com/ testimonials.php to read real quotes from published authors. 